\title{
Physical Activity Level, Anthropometric and Cardiovascular Profile Among Students in Sergipe State Attending Public Schools
}

\author{
Luan Morais Azevêdo, ${ }^{1 \oplus}$ Lucas Souza Santos, $^{2 @}$ Emerson Pardono, ${ }^{2 \oplus}$ Jeeser Alves Almeida, ${ }^{3 \oplus}$ Aldemir Smith \\ Menezes 2,4 (1) \\ Universidade de São Paulo (USP), ${ }^{1}$ Escola de Educação Física e Esporte da Universidade de São Paulo (EEFE-USP), São Paulo, SP - Brazil. \\ Universidade Federal de Sergipe (UFS), ${ }^{2}$ Programa de Pós-graduação em Educação Física, São Cristóvão, SE - Brazil; \\ Universidade Federal do Mato Grosso do Sul (UFMS), ${ }^{3}$ Programa de Pós-Graduação em Saúde e Desenvolvimento na Região Centro Oeste, Campo \\ Grande, MS - Brazil. \\ Instituto Federal de Educação, Ciência e Tecnologia de Sergipe (IFS), ${ }^{4}$ Aracaju, SE - Brazil.
}

\section{Abstract}

Background: Cardiovascular diseases are the leading cause of mortality among adults. Evidence has shown that sedentary behaviors are the main preventable outcome, however, many sedentary children also become sedentary adults. Therefore, identifying potential risk factors as early as possible contributes to therapeutic success.

Objective: To achieve an anthropometric and cardiovascular mapping of school-age students from Sergipe State, Brazil.

Methods: A school-based cross-sectional study with a representative sample from public schools in the state of Sergipe $(n=4700)$. Anthropometric and blood pressure measurements were performed, and the Global Schoolbased Student Health Survey was used to assess the physical activity level. An independent samples t-test was performed for all comparisons, and significance was established at $5 \%(\mathrm{p}<0.05)$.

Results: Despite showing mean blood pressure values within reasonable limits $(\mathrm{SBP}=114.1 \pm 12.4 \mathrm{~mm} \mathrm{Hg}$ and $\mathrm{DBP}=66.3 \pm 8.1 \mathrm{~mm} \mathrm{Hg}$ ), school-age students did not comply with global recommendations for health promotion. It was also observed a high rate of low body weight $(42.6 \%)$, suggesting dietary compromises, which can interfere with the development of this population. In addition, only $7.3 \%$ of students met the minimum physical activity criteria proposed for maintaining their health status.

Conclusion: The findings of the present study emphasize the importance of maintaining Physical Education classes as an essential curricular component, since they provide several health benefits and ensure that this population reaches the minimum daily recommendations, preventing diseases in adult life. (Int J Cardiovasc Sci. 2021; 34(3):255-261)

Keywords: Students; Adolecents; Public Schools; Anthropometry; Exercise; Risk Factors; Hypertension; Sedentarism; Epidemiology; Prevalence.

\section{Introduction}

Data from the World Health Organization ${ }^{1}$ show that systemic arterial hypertension (SAH) affects about $30 \%$ of the world population, and the Brazilian Society of Cardiology reports that about 3 to $5 \%$ of school-age individuals are hypertensive, which is attributed to the increased rates of obesity in this population ${ }^{2}$. Besides, most individuals who were hypertensive in childhood/ adolescence remain hypertensive adults ${ }^{3}$. 
$\mathrm{SAH}$ is a chronic non-communicable disease, in which biological, behavioral, and socioeconomic factors lead to blood pressure values higher than 120 and 80 $\mathrm{mmHg}$ for systolic (SBP) and diastolic (DBP) pressures, respectively ${ }^{2,4,5}$. However, strategies for the control and treatment of hypertension can be adopted to prevent it from remaining in adulthood.

These strategies include the promotion of public policies for prevention (primary care), pharmacological interventions (e.g. antihypertensive drugs), and nonpharmacological interventions, which include dietary changes $^{6}$ and physical exercise ${ }^{7}$. The latter were identified as the most effective and safe, because they did not show as many side effects when compared to pharmacological interventions, mainly in children. Besides, the effects of exercise may be as effective as those of antihypertensive drugs ${ }^{8}$.

Therefore, the identification of risk factors associated with hypertension is essential for disease prevention and maintenance of quality of life in this population, reducing the burden on health care resources. In this sense, the present study aimed to identify the physical activity level and to trace the anthropometric and cardiovascular profile of a representative sample of school-age students attending public schools in the state of Sergipe, Brazil.

\section{Methods}

\section{Characterization of the Study}

A cross-sectional epidemiological study including students enrolled in public schools was conducted in the 8 geographic territories of the state of Sergipe, Brazil. The local Research Ethics Committee approved the present study under number 1522.876/2016/CEP/CONEP/CNS.

\section{Research Field}

The state of Sergipe is located in the northeastern region of Brazil and has a territorial area of 21,925,424 $\mathrm{km}^{2}$, with approximately 2,298,696 inhabitants. In addition, the state is composed of 75 counties, being geographically divided into 8 territories. Each territory has similar characteristics for 15 variables and 79 indicators distributed in the following dimensions: economic-productive, social, political-institutional, sociocultural, and environmental.

Considering the government actions that lead rural school-age students to study in the city (urban zone), as well as the similarity in pedagogical proposals and organization within each territory, there is a reduction in the possibility of selection bias due to the equivalence of some characteristics of the sample. For these reasons, it is believed that the random selection of counties as well as of education units (territories) clearly represents the group of school-age students in the state of Sergipe. In this context, proportionality by territory, education unit size, school grades, and study shift justify the methodology adopted for sample selection (Table 1).

\section{Population and Sample}

Stratified random sampling was used to select the desired sample. First, the primary unit was determined by considering the minimum sample needed for the study and stratified proportionally to the territory and size of the school ( 1 = up to 199 students, $2=200-499$ students, $3=500+$ students). Besides, for all territories to be considered representatively with the 3 school sizes, an amount of $25 \%$ of the study units (160 study units) was established as a criterion, totaling 42 schools distributed in 30 counties. After this, the secondary unit consisted of schools selected according to school grade and study shift (day or evening), using a simple random process and considering 20 students per school grade.

It should be pointed out that to maintain sample representativeness, for reasons such as participant refusal, age above or below that established in this study, and/or not answering important questions (i.e., sex and age), $10 \%$ was added to the total desired sample.

Table 1 - Sample stratification by territories of the state of Sergipe $(n=4151)$

\begin{tabular}{lcc}
\hline Territory & $\mathbf{n}$ & $\mathbf{\%}$ \\
\hline Grande Aracaju & 1043 & 25.1 \\
\hline Sul Sergipano & 450 & 10.8 \\
\hline Agreste Sergipano & 491 & 11.8 \\
\hline Centro Sul Sergipano & 303 & 7.3 \\
\hline Leste Sergipano & 300 & 7.2 \\
\hline Médio Sertão Sergipano & 391 & 9.4 \\
\hline Baixo São Francisco & 627 & 15.1 \\
\hline Alto Sertão Sergipano & 546 & 13.2 \\
\hline Total & 4151 & 100 \\
\hline
\end{tabular}




\section{Inclusion/Exclusion Criteria}

Participants included students of both sexes, aged 14 to 19 years, who voluntarily joined the study, according to the following criteria: be regularly enrolled in the selected schools; be present at the time of the evaluation; and fill in the questionnaire adequately, reducing nonresponses as much as possible. Students whose parents did not sign the negative consent form (Parental Passive Consent Form) and who did not answer questions such as sex and age were excluded.

\section{Instrumentation and Data Collection}

For anthropometric measurements, body mass and height measurements were used to estimate body mass index (BMI), and waist circumference (WC) and hip circumference (HR) were used to estimate the waist-tohip ratio (WHR), following the WHO criteria and cut-off points 9 . Also, measurements of systolic blood pressure (SBP), diastolic blood pressure (DBP), and heart rate (HR) were performed using a calibrated and validated automated monitor (OMRON Healthcare brand, HEM720, Kyoto - Japan) ${ }^{10}$, adopting the Brazilian Society of Cardiology criteria and cut-off points ${ }^{2}$.

The physical activity level was estimated from the Global School-based Student Health Survey (GSHS/WHO), using recommendations for each age group as criteria for analysis ${ }^{11}$. It should be pointed out that all procedures were performed by 2 trained evaluators/class, and each class teacher was asked to remain in class to maintain their well-being as well.

\section{Statistical Procedures}

Data were expressed using descriptive statistics, such as absolute and relative frequency for categorical variables and mean and standard deviation for continuous variables. Normality and heterogeneity were assessed by the Shapiro-Wilk and Levene tests, respectively. In order to verify differences between the sexes, Student t-test for independent samples was applied. Also, the criteria proposed by Cole et al., ${ }^{12}$ were adopted for BMI categorization. All procedures were performed using SPSS, version 22 , and significance was established at $\mathrm{p}<0.05$.

\section{Results}

A total of 4700 school-age students, of both sexes, were evaluated. However, due to non-compliance with some of the inclusion criteria, 549 of these were excluded from the sample, accounting for a final sample of 4151 individuals. The general characteristics of the study sample are shown in Table 2.

In general, students presented BMI in the "normal weight" category $\left(22.1 \pm 4.0 \mathrm{~kg} / \mathrm{m}^{2}\right)$, WHR in the "low risk" category $(0.8 \pm 0.1)$, and values within the reference range for both SBP $(114.1 \pm 12.4 \mathrm{mmHg})$ and DBP (66.3 $\pm 8.1 \mathrm{mmHg})$.

Table 3 shows the absolute and relative frequencies of school-age students who performed at least $60 \mathrm{~min}$ of moderate to vigorous physical activity. It can be observed that $83.5 \%$ ( 0 to 4 days) of the sample does not meet the recommendations proposed by the $\mathrm{WHO}$ and that only $7.3 \%$ engaged in moderate to vigorous physical activity for at least 60 min daily.

The same pattern was observed for both boys (42.9\%) and girls (42.3\%), with age ranging from 16 to 17 years, and compared to the BMI categories of the same age group, as well as among the other age groups (Table 4).

Table 5 shows blood pressure values stratified by sex and age groups. Significant differences were found between the sexes for SBP in all age groups. Regarding DBP, only the category " $\leq 15$ years" presented

Table 2 - General anthropometric and hemodynamic characteristics of the sample $(n=4151)$

\begin{tabular}{|c|c|c|c|}
\hline & Mean & $\pm \mathrm{SD}$ & $95 \%$ CI \\
\hline \multicolumn{4}{|l|}{ Anthropometric } \\
\hline Body Mass (kg) & 59.5 & 12.4 & $59.1-59.9$ \\
\hline Height (m) & 1.6 & 0.1 & $1.63-1.64$ \\
\hline Body Mass Index $\left(\mathrm{kg} / \mathrm{m}^{2}\right)$ & 22.1 & 4.0 & $22.0-22.2$ \\
\hline $\mathrm{WC}(\mathrm{cm})$ & 72.3 & 8.8 & $72.0-72.5$ \\
\hline $\mathrm{HC}(\mathrm{cm})$ & 92.4 & 9.5 & $92.1-92.7$ \\
\hline WHR & 0.8 & 0.1 & $0.78-0.79$ \\
\hline \multicolumn{4}{|l|}{ Cardiovascular } \\
\hline SBP (mmHg) & 114.1 & 12.4 & $\begin{array}{c}113.7- \\
114.5\end{array}$ \\
\hline DBP (mmHg) & 66.3 & 8.1 & $66.0-66.5$ \\
\hline HR (bpm) & 82.2 & 12.9 & $81.8-82.6$ \\
\hline
\end{tabular}




\begin{tabular}{|c|c|c|}
\hline & $\mathbf{n}$ & $\%$ \\
\hline \multicolumn{3}{|l|}{$\leq 15$ years } \\
\hline 0 day & 226 & 5.5 \\
\hline 1 to 2 days & 287 & 7.0 \\
\hline 3 to 4 days & 125 & 3.1 \\
\hline 5 to 6 days & 63 & 1.5 \\
\hline 7 days & 47 & 1.1 \\
\hline \multicolumn{3}{|c|}{16 - 17 years } \\
\hline 0 day & 693 & 16.9 \\
\hline 1 to 2 days & 798 & 19.5 \\
\hline 3 to 4 days & 334 & 8.2 \\
\hline 5 to 6 days & 206 & 5.0 \\
\hline 7 days & 160 & 3.9 \\
\hline \multicolumn{3}{|c|}{18 - 19 years } \\
\hline 0 day & 339 & 8.3 \\
\hline 1 to 2 days & 460 & 11.2 \\
\hline 3 to 4 days & 160 & 3.9 \\
\hline 5 to 6 days & 104 & 2.5 \\
\hline 7 days & 96 & 2.3 \\
\hline Total & 4098 & 100 \\
\hline $\begin{array}{l}\text { a difference } \\
\text { analyzed var }\end{array}$ & ue to $\mathrm{mi}$ & the \\
\hline
\end{tabular}

differences between the sexes, $65.6 \pm 8.1 \mathrm{mmHg}$ vs. $63.7 \pm 7.6 \mathrm{mmHg}$, for boys and girls, respectively. The HR values were higher $(p=0.001)$ in boys of all age groups (Table 5).

After the BMI stratification, it was evidenced that the individuals with lower body mass had lower blood pressure values, $112.8 \pm 12.0$ and $65.5 \pm 7.8 \mathrm{mmHg}$, respectively, for SBP and DBP, compared to normal weight $(118.1 \pm 12.6$ and $68.2 \pm 8.2 \mathrm{mmHg})$ and overweight $(112.2 \pm 12.8$ and $71.2 \pm 8.9 \mathrm{mmHg})$ individuals. Table 6 also shows the differences between SBP and DBP between normal weight $(118.1 \pm 12.6$ and $68.2 \pm 8.2 \mathrm{mmHg}$, respectively) and overweight students (122.2 \pm 12.8 and $71.2 \pm 8.9 \mathrm{mmHg}$, respectively).

\begin{tabular}{|c|c|c|c|c|}
\hline \multicolumn{5}{|c|}{$\begin{array}{l}\text { Table } 4-\text { General BMI of the sample, stratified by age } \\
\text { range and } \operatorname{sex}(n=4141)^{\mathrm{a}}\end{array}$} \\
\hline & \multicolumn{2}{|c|}{ Male } & \multicolumn{2}{|c|}{ Female } \\
\hline & $\mathrm{n}$ & $\%$ & $\mathbf{N}$ & $\%$ \\
\hline \multicolumn{5}{|l|}{$\leq 15$ years } \\
\hline Low Weight & 354 & 14.8 & 224 & 12.8 \\
\hline Normal Weight & 90 & 3.8 & 44 & 2.5 \\
\hline Overweight & 32 & 1.3 & 10 & 0.6 \\
\hline \multicolumn{5}{|l|}{16 - 17 years } \\
\hline Low Weight & 1024 & 42.9 & 743 & 42.3 \\
\hline Normal Weight & 205 & 8.6 & 115 & 6.6 \\
\hline Overweight & 79 & 3.3 & 47 & 2.7 \\
\hline \multicolumn{5}{|l|}{18 - 19 years } \\
\hline Low Weight & 450 & 18.9 & 451 & 25.7 \\
\hline Normal Weight & 105 & 4.4 & 90 & 5.1 \\
\hline Overweight & 47 & 2.0 & 31 & 1.8 \\
\hline Total & 2386 & 100 & 1755 & 100 \\
\hline $\begin{array}{l}\text { a difference betwee } \\
\text { analyzed variable }\end{array}$ & initial & edue to & tg case & \\
\hline
\end{tabular}

\section{Discussion}

Several studies demonstrate the importance of physical activity, especially in the early stages of life, since it can promote increased academic performance ${ }^{13}$, maintenance of glucose levels ${ }^{14}$, lipid profile ${ }^{15}$, and blood pressure ${ }^{16}$, with consequent attenuation of diabetes, obesity, and hypertension, respectively. It also acts in the treatment and prevention of depression ${ }^{17}$, among other benefits. Nevertheless, the present study found high rates of insufficient physical activity for both boys and girls, among school-age students in the state of Sergipe.

These indices reveal that Brazilian public policies appear to be ineffective in promoting health at the primary care level, addressing it only when issues reach a permanent status, which in turn leads to an excessive burden on the Brazilian public health system ${ }^{18}$.

The "16 to 17 years" age group presented high rates of low body weight, both when compared to the other age categories, as well as between the sexes of the same 
Table 5 - Cardiovascular variables of the sample, stratified by age range and sex $(n=4151)$

\begin{tabular}{|c|c|c|c|c|c|}
\hline & \multicolumn{2}{|c|}{ Boys } & \multicolumn{2}{|c|}{ Girls } & \multirow{2}{*}{$\mathrm{p}$} \\
\hline & Mean & $\pm \mathrm{SD}$ & Mean & $\pm \mathrm{SD}$ & \\
\hline \multicolumn{6}{|l|}{ SBP (mmHg) } \\
\hline$\leq 15$ years & 108.9 & 10.8 & 116.2 & 12.1 & $0.001^{*}$ \\
\hline 16 - 17 years & 109.2 & 10.1 & 120.2 & 12.4 & $0.001^{*}$ \\
\hline 18 - 19 years & 111.0 & 10.9 & 122.3 & 11.4 & $0.001^{*}$ \\
\hline \multicolumn{6}{|c|}{ DBP (mmHg) } \\
\hline$\leq 15$ years & 65.6 & 8.1 & 63.7 & 7.6 & $0.001^{*}$ \\
\hline 16 - 17 years & 66.1 & 7.6 & 65.9 & 8.2 & 0.663 \\
\hline 18 - 19 years & 67.7 & 8.1 & 67.5 & 8.4 & 0.634 \\
\hline \multicolumn{6}{|l|}{ HR (bpm) } \\
\hline$\leq 15$ years & 87.3 & 12.0 & 80.8 & 13.0 & $0.001^{*}$ \\
\hline 16 - 17 years & 85.5 & 11.7 & 78.5 & 13.2 & $0.001^{*}$ \\
\hline 18 - 19 years & 83.9 & 11.6 & 74.7 & 12.0 & $0.001^{*}$ \\
\hline
\end{tabular}

Table 6 - Cardiovascular variables of the sample, stratified by BMI categories $(n=4151)$

\begin{tabular}{|c|c|c|c|}
\hline & Mean & $\pm \mathrm{SD}$ & $95 \%$ CI \\
\hline \multicolumn{4}{|l|}{ SBP (mmHg) } \\
\hline Low Weight & 112.8 & 12.0 & $112.3-113.2$ \\
\hline Normal Weight & $118.1^{+}$ & 12.6 & $117.1-119.0$ \\
\hline Overweight & $122.2^{++}$ & 12.8 & $120.6-123.8$ \\
\hline \multicolumn{4}{|l|}{ DBP (mmHg) } \\
\hline Low Weight & 65.5 & 7.8 & $65.2-65.8$ \\
\hline Normal Weight & $68.2^{+}$ & 8.2 & $67.6-68.8$ \\
\hline Overweight & $71.2^{++}$ & 8.9 & $70.2-72.2$ \\
\hline \multicolumn{4}{|l|}{ HR (bpm) } \\
\hline Low Weight & 82.1 & 13.0 & $81.7-82.6$ \\
\hline Normal Weight & 81.9 & 12.6 & $80.9-82.9$ \\
\hline Overweight & 83.5 & 11.6 & $81.8-85.1$ \\
\hline
\end{tabular}


age category. The results of the present study differed partially from those obtained by Reuter et al., ${ }^{19}$ who found a high prevalence of overweight/obesity in schoolage students in the city of Santa Cruz, Brazil (South region), with a higher susceptibility to cardiovascular risks compared to eutrophic students and those with low body weight. This fact evidences a discrepancy between the Brazilian South and Northeast regions. However, both presented increased risk factors in this population.

The study conducted by de Almeida Silva et al., ${ }^{20}$ showed a positive association between low consumption of fruits and vegetables and low levels of physical activity, which may have triggered the unfavorable nutritional status of the sample studied. Furthermore, the low consumption of fruits, vegetables, and legumes is associated with higher consumption of processed beverages, such as juices and soft drinks, which contain high sugar, sodium, food dyes, and preservatives, which in turn may contribute to cases of SAH.

Based on this premise, a study conducted in Belo Horizonte, state of Minas Gerais ${ }^{21}$, evaluated the implementation and effectiveness of 2 programs to change the behavior of school-age students from 6 to 11 years old. After the implementation of the programs, the researchers observed a significant improvement in the behavior of students, who started to adopt a more active lifestyle. The results obtained by Ribeiro and Alves ${ }^{21}$ reinforce the importance of public policies focused on primary care to avoid chronic diseases and comorbidities associated with these pathologies.

In the present study, the cardiovascular variables differed between the sexes and the BMI categories. Besides, low levels of physical activity associated with an inadequate diet can trigger chronic diseases, such as obesity and hypertension, which can persist into adulthood ${ }^{3}$. Furthermore, a meta-analysis conducted by Gonçalves et al. ${ }^{22}$ showed that the South region of Brazil has the highest prevalence of hypertension in adolescents (12.4\%), followed by the Northeast (10\%) and North (6.9\%), while the Southeast and Midwest regions had the lowest scores, 4.3 and $3 \%$, respectively. The Brazilian government can use the findings of Gonçalves et al., ${ }^{22}$ to direct health actions to mitigate these indices.

This study has some limitations, such as not using direct methods for measuring physical activity levels, although the instrument used presents high reliability in obtaining this variable in epidemiological studies, and the measurement of blood pressure in the classroom. However, the results obtained for this variable have high ecological validity, since they were obtained under real conditions of analysis.

\section{Conclusions}

Although no significant manifestations of obesity were revealed, students from the state of Sergipe showed insufficient levels of physical activity, despite the high levels of low body weight. Thus, after this epidemiological mapping, we suggest the development of strategies to increase physical activity in Physical Education classes, as well as health education policies for students in Sergipe State attending public schools to raise awareness of healthy habits that can contribute to the prevention of chronic diseases.

\section{Potential Conflict of Interest}

No potential conflict of interest relevant to this article was reported.

\section{Sources of Funding}

There were no external funding sources for this study.

\section{Study Association}

This study is not associated with any thesis or dissertation work.

\section{Ethics Approval and Consent to Participate}

This study was approved by the Ethics Committee of the Instituto Federal de Educação, Ciência e Tecnologia (IFS) under the protocol number 1522.876/2016/CEP/CONEP/ CNS. All the procedures in this study were in accordance with the 1975 Helsinki Declaration, updated in 2013. Informed consent was obtained from all participants included in the study.

\section{Author contributions}

Conception and design of the research: Azevêdo LM, Santos LS, Pardono E, Almeida JA, Menezes AS. Acquisition of data: Azevêdo LM, Santos LS. Analysis and interpretation of the data: Azevêdo LM, Santos LS, Pardono E, Almeida JA, Menezes AS. Statistical analysis: Azevêdo LM, Santos LS, Pardono E, Almeida JA, Menezes AS. Writing of the manuscript: Azevêdo LM, Santos LS, Pardono E, Almeida JA, Menezes AS. Critical revision of the manuscript for intellectual content: Pardono E, Almeida JA, Menezes AS. 


\section{References}

1. World Health Organization (WHO). A Global Brief on Hypertension. Geneva: 2013. 40 p.

2. Malachias M, Souza W, Plavnik F, Rodrigues C, Brandão A, Neves M, et al. VII Diretriz Brasileira de Hipertensão Arterial. Arq Bras Cardiol. 2016;107(3):1-103.

3. Chen X, Wang Y. Tracking of blood pressure from childhood to adulthood: A systematic review and meta-regression analysis. Circulation. 2008;117(25):3171-80.

4. Wang B, Liao C, Zhou B, Cao W, Lv J, Yu C, et al. Genetic contribution to the variance of blood pressure and heart rate: a systematic review and meta-regression of twin studies. Twin Res Hum Genet. 2015;18(2):158-70.

5. Perin MS, Cornélio ME, Rodrigues RCM, Gallani MCBJ. Caracterização do consumo de sal entre hipertensos segundo fatores sociodemográficos e clínicos. Rev Lat Am Enfermagem. 2013;21(5):1-9.

6. Tebar WR, Ritti-Dias RM, Farah BQ, Zanuto EF, Vanderlei LCM, Christofaro DGD. High blood pressure and its relationship to adiposity in a school-aged population: body mass index vs waist circumference. Hypertens Res. 2018;41(2):135-40.

7. Cornelissen VA, Smart NA. Exercise training for blood pressure: a systematic review and meta-analysis. J Am Heart Assoc. 2013;2(1):e004473.

8. Naci H, Salcher-Konrad M, Dias S, Blum MR, Sahoo SA, Nunan D, et al. How does exercise treatment compare with antihypertensive medications? A network meta-analysis of 391 randomised controlled trials assessing exercise and medication effects on systolic blood pressure. Br J Sports Med. 2018;bjsports-2018-099921.

9. World Health Organization. (WHO). Waist Circumference and Waist-Hip Ratio: Report of a WHO Expert Consultation. Geneva; 2008.39p.

10. Topouchian J, Agnoletti D, Blacher J, Youssef A, Ibanez I, Khabouth J, et al. Validation of four automatic devices for self-measurement of blood pressure according to the international protocol of the European Society of Hypertension. Vasc Health Risk Manag. 2011;7(1):709-17.

11. World Health Organization, (WHO). Global School-Based Student Health Survey (GSHS) CORE QUESTIONNAIRE MODULES. Geneva;2009;

12. Cole T, Bellizzi M, Flegal K, Dietz W. Establishing a standard definition for child overweight and obesity worldwide: international survey. BMJ. 2000;320(7244):1240-3
13. de Greeff JW, Bosker RJ, Oosterlaan J, Visscher C, Hartman E. Effects of physical activity on executive functions, attention and academic performance in preadolescent children: a meta-analysis. J Sci Med Sport. 2018;21(5):501-7.

14. Wheeler MJ, Dempsey PC, Grace MS, Ellis KA, Gardiner PA, Green DJ, et al. Sedentary behavior as a risk factor for cognitive decline? A focus on the influence of glycemic control in brain health. Alzheimer's Dement Transl Res Clin Interv. 2017;3(3):291-300.

15. Yoon J-G, Kim S-H, Rhyu H-S. Effects of 16-week spinning and bicycle exercise on body composition, physical fitness and blood variables of middle school students. J Exerc Rehabil. 2017;13(4):400-4.

16. Cardoso CG, Gomides RS, Queiroz ACC, Pinto LG, da Silveira Lobo F, Tinucci $\mathrm{T}$, et al. Acute and chronic effects of aerobic and resistance exercise on ambulatory blood pressure. Clinics (Sao Paulo). 2010;65(3):317-25.

17. Gujral S, Aizenstein H, Reynolds CF, Butters MA, Erickson KI. Exercise effects on depression: Possible neural mechanisms. Gen Hosp Psychiatry. 2017;49:2-10.

18. Bielemann RM, da Silva BGC, Coll C de VN, Xavier MO, da Silva SG. Burden of physical inactivity and hospitalization costs due to chronic diseases. Rev Saude Publica. 2015:49:75.

19. Reuter CP, Burgos LT, Camargo MD, Possuelo LG, Reckziegel MB, Reuter EM, et al. Prevalence of obesity and cardiovascular risk among children and adolescents in the municipality of Santa Cruz do Sul, Rio Grande do Sul. Sao Paulo Med J. 2013;131(5):323-30.

20. de Almeida Silva FM, Menezes AS, da Silva Duarte M de F. Consumption of fruits and vegetables associated with other risk behaviors among adolescents in Northeast Brazil. Rev Paul Pediatr (English Ed. 2016;34(3):309-15.

21. Ribeiro RQ, Alves L. Comparison of two school-based programmes for health behaviour change: the Belo Horizonte Heart Study randomized trial. Public Health Nutr. 2014;17(06):1195-204.

22. Gonçalves VSS, Galvão TF, de Andrade KRC, Dutra ES, Bertolin MNT, de Carvalho KMB, et al. Prevalence of hypertension among adolescents: systematic review and meta-analysis. Rev Saude Publica. 2016;50:27. 